\title{
The structure and function of the rhizosphere microbial communities of Carex praeclara and Leymus secalinus in a Zoige alpine grassland
}

\author{
TingKun $\operatorname{Jian}^{1}$, Yue Xia ${ }^{1}$, Ruipeng $\mathrm{He}^{1}$, and Jie zhang ${ }^{1}$ \\ ${ }^{1}$ Sichuan University
}

September 25, 2021

\begin{abstract}
Rhizosphere microorganisms are thought to play a crucial role in the promotion of plant growth and health. Carex praeclara and Leymus secalinus are dominant plant species that have colonized the desertification land of Alpine wetland grasslands in Zoige. There is a lack of comprehensive research on their rhizosphere microbes. In this study, we used deep shotgun metagenomic sequencing to analyze the microbial community and functional composition of the rhizosphere and corresponding non-rhizosphere soils of C. praeclara and L. secalinus. The microbial diversity and structure exhibited a remarkable difference among the rhizosphere and non-rhizosphere samples, and the predominant taxa included Actinobacteria, Proteobacteria, Acidobacteria and Chloroflexi in all the samples. Genes that were over-represented include those involved in the acquisition of nutrients, stress responses, transposable elements and plant growth promotion suggest that the interactions between microbe-plant and microbe-microbe are more intense in the rhizosphere soil. The relative abundances of pivotal genes that participate in microbial nitrogen $(\mathrm{N})$ and phosphorus $(\mathrm{P})$ transformation were higher in the rhizosphere soil than in the non-rhizosphere soil, indicating the enhancement of potential soil N- and P-cycling in the plant rhizosphere. Our findings provide valuable information on the structure and function of the microbial communities of the C. praeclara and L. secalinus rhizospheres and lay a foundation for the further use of C. praeclara and L. secalinus to increase vegetation coverage, improve soil properties and restore the ecological function of degraded alpine sandy land.
\end{abstract}

The structure and function of the rhizosphere microbial communities of Carex praeclara and Leymus secalinus in a Zoige alpine grassland

Tingkun Jian, Yu Xia, Ruipeng He, Jie Zhang*

Key Laboratory of Biological Resources and Ecological Environment of Ministry of Education, College of Life Sciences, Sichuan University, Chengdu, PR China

*Correspondence

Jie Zhang, Key Laboratory of Biological Resources and Ecological Environment of Ministry of Education, College of Life Sciences, Sichuan University, Chengdu 610064, PR China

Email: zhangjfy@163.com

\section{Short informative title}

The microbial composition and metabolic function of rhizosphere microbiome of Carex praeclara and Leymus secalinus differ from that of non-rhizosphere soil

Short running title 
Metagenomic analysis of pioneer plants rhisphohere microbiome

\title{
Funding information
}

The Second Tibetan Plateau Scientific Expedition and Research Program, Grant/Award Number: 2019QZKK0404.

\begin{abstract}
Rhizosphere microorganisms are thought to play a crucial role in the promotion of plant growth and health. Carex praeclara andLeymus secalinus are dominant plant species that have colonized the desertification land of Alpine wetland grasslands in Zoige. There is a lack of comprehensive research on their rhizosphere microbes. In this study, we used deep shotgun metagenomic sequencing to analyze the microbial community and functional composition of the rhizosphere and corresponding non-rhizosphere soils of C. praeclara and L. secalinus. The microbial diversity and structure exhibited a remarkable difference among the rhizosphere and non-rhizosphere samples, and the predominant taxa included Actinobacteria, Proteobacteria, Acidobacteria and Chloroflexi in all the samples. Genes that were over-represented include those involved in the acquisition of nutrients, stress responses, transposable elements and plant growth promotion suggest that the interactions between microbe-plant and microbe-microbe are more intense in the rhizosphere soil. The relative abundances of pivotal genes that participate in microbial nitrogen $(\mathrm{N})$ and phosphorus $(\mathrm{P})$ transformation were higher in the rhizosphere soil than in the non-rhizosphere soil, indicating the enhancement of potential soil N- and P-cycling in the plant rhizosphere. Our findings provide valuable information on the structure and function of the microbial communities of the C. praeclara and L. secalinus rhizospheres and lay a foundation for the further use of $C$. praeclara and $L$. secalinus to increase vegetation coverage, improve soil properties and restore the ecological function of degraded alpine sandy land.
\end{abstract}

\section{KEYWORDS}

Carex praeclara, Leymus secalinus, metagenomic analysis, rhizosphere microbial communities; metabolic pathway

\section{1 | INTRODUCTION}

Soil microorganisms play essential roles in biogeochemical processes, such as soil formation and element cycling (Liu et al ., 2020). The rhizosphere soil harbors extensive and varied microbes, some of which are defined as plant growth-promoting rhizobacteria (PGPR) (Bhattacharyya \& Jha, 2012) and benefit plants by a wide variety of mechanisms, including the secretion of phytohormones, enhancement of resistance to stress, assistance in acquiring nutrients and prevention of pathogenic infections (Bashan \& De-Bashan, 2010). The root-associated soil contains various organic compounds, including low molecular weight primary and secondary metabolites, enzymes and other substances secreted by plant roots. These exudates provide nutrition and vitamins for the microbes and drive the assembly of the microbial community in the rhizosphere (Liu et al ., 2021). Therefore, the interactions between plants and rhizosphere microbes are crucial to the promotion of plant growth and recovery of disturbed ecosystems.

The Zoige alpine grassland, located in the eastern edge of the Qinghai Tibet Plateau, is an important animal husbandry base and also a water conservation area of the Yellow River and the Yangtze River in China. It plays a very important role in nutrient cycling and regional climate regulation. Owing to frequent anthropogenic activities and climate change, the diversity of vegetation of the grasslands has decreased remarkably, and extensive grasslands have even degraded into deserts during the previous few decades $(\mathrm{Yu}$ et al ., 2020). Ecological restoration is thought to be an efficient strategy to improve biodiversity and ecological functions (Guo et al ., 2021). Since the 1990s, a serious of restoration programs have been implemented in the Zoige alpine grassland to alleviate the desertification, restore biodiversity and maintain the ecological balance (Fang et al. , 2020). Different measures have been taken based on the severity of desertification, including the establishment of biological sand barriers, the replanting of grass seeds, the application of organic fertilizer and the creation of an enclosure fence (Yu et al ., 2016). 
Pioneer plants are those species that first colonize a newly disturbed habitat caused by natural or anthropogenic factors (Ye et al ., 2021) and subsequently support the colonization of other plants (Rincón-Molina et al ., 2020). Carex praeclara andLeymus secalinus are indigenous pioneer plants in the Zoige alpine grassland and can grow on severely desertified soil and even on moving sand dunes (Kang et al ., 2017). Their tolerance to drought and barren soil and their capacity to reproduce asexually render them potential plant species to solve desertification.

The taxonomic and functional profiling of the rhizosphere microbiome has largely focused on cash crops, such as citrus (Xu et al ., 2018), soybean (Mendes et al ., 2014), corn (Walters et al ., 2018) and rice (Zhang et al ., 2019), whereas there is limited information on the study of plants that colonize desertified grassland in the Zoige alpine grassland. In this study, we compared the structure and function of the rhizosphere soil microbiome of $C$. praeclaraand $L$. secalinus with the associated non-rhizosphere soil microbiome using shotgun metagenomic sequencing approaches. We present the results of a comparative analysis in microbiome composition and functional features. These results will further improve the understanding of the mechanisms of interaction between pioneer plants and rhizosphere-associated microbes and also lay a foundation for the application of $C$. praeclara and L. secalinus to improve desertification.

\section{2 | MATERIALS AND METHODS}

\section{1 | Sampling}

We collected samples from three locations of alpine desertified grasslands that only harbored C. praeclara

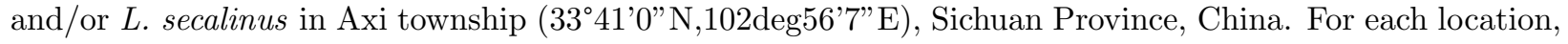
10 healthy $C$. praeclara and L. secalinus plants were randomly selected. The topsoil was removed, and then the plants were carefully dug out. The roots were lightly shaken to remove the sandy soil that was not firmly attached, and the remaining soil that was firmly attached was designated the rhizosphere soil, which was brushed with a sterile brush and then collected. The soil without roots from a depth of 10-15-cm around the selected plants was collected and designated the non-rhizosphere soil. The rhizosphere soil of 10 plants and the corresponding bulk soil from each area were mixed up together to form one sample. Altogether, six rhizosphere and three non-rhizosphere soil samples were obtained. A portion of each sample was stored in liquid nitrogen until the DNA was extracted, and the remaining portion was analyzed for its physicochemical properties. Finally, the sampled plants were replanted in the sandy soil.

\section{2 | Soil physicochemical analyses}

To evaluate the nutritional conditions of the desertification soil, the following physicochemical characteristics were analyzed. The soil pH was measured in water using a PHS-3S pH meter (INESA \& Scientific Instrument, Shanghai, China) with a ratio of 1:2.5 soil: deionized water $(\mathrm{v} / \mathrm{v})$. The available potassium (AK), total potassium (TK), available phosphorus (AP), total phosphorus (TP), organic carbon (OC), total nitrogen $(\mathrm{TN})$, ammonium $\left(\mathrm{NH}_{4}{ }^{+} \mathrm{N}\right)$ and nitrate $\left(\mathrm{NO}_{3}-\mathrm{N}\right)$ were measured as previously described (Zhang et al ., 2015).

\section{3 | DNA extraction and sequencing}

The DNA was extracted from each soil sample using a MOBIO PowerSoil(r) DNA Isolation Kit (Carlsbad, CA, USA) following the manufacturer's instructions. The quality of DNA was analyzed on $1.0 \%$ agarose gels, and the concentration of DNA was simultaneously measured using Qubit 2.0 (Thermo Fisher Scientific, Waltham, MA, USA). The sequencing libraries were generated using an NEB Next(r) Ultra DNA Library Prep Kit for Illumina(r) (New England Biolabs, Beverly, MA, USA) following the manufacturer's instructions, and index codes were added. After quality assessment, the libraries were then sequenced on an Illumina HiSeq X-10 platform (Illumina, San Diego, CA) (Deng et al ., 2020)\{Deng, 2020 \#68\}, and 150 bp pairedend reads were generated. The Raw Data processing was conducted using Trimmomatic (v.0.36) to generate the Clean Data, which was subsequently assembled using MEGAHIT (v.1.0.6). The assembled scaffolds were broken from the N connection to obtain the Scaftigs. The fragments $<500$ bps of all the Scaftigs were used for statistical analysis. 


\section{4 | Taxonomic profiling}

The Scaftigs ([?] $500 \mathrm{bp}$ ) were all used to predict their Open Reading Frame (ORF) using MetaGeneMark (v.3.38) (Oh et al ., 2014). CD-HIT software (v.4.7) was adopted to remove redundancy and obtain the unique initial gene catalogue. The genes were clustered by identity $95 \%$ and coverage $90 \%$ and the longest sequence as the representative sequence was chosen. BBMAP software was used to map the clean date of each sample to the initial gene catalogue. The abundance of each gene in each sample was determined based on the number of mapped reads and the length of genes. To obtain the taxonomic annotation of each unigene, DIAMOND software was utilized to BLAST the unigenes to the sequences of bacteria, fungi, archaea and viruses that were all extracted from the NR database of the NCBI (Buchfink et al ., 2015). The finally aligned result was chosen from the multiple aligned results of each sequence on the condition that the e value was $1 \mathrm{e}^{-10}$. The lowest common ancestor (LCA) algorithm, which was applied in MEGAN, was used to generate the taxonomic annotation of the unigenes and calculate the relative abundance of each taxon.

\section{5 | Function annotations}

DIAMOND was utilized to BLAST the unigenes to functional databases, including the Kyoto Encyclopedia of Genes and Genomes (KEGG) (Kanehisa \& Goto, 2000) and carbohydrate-active genes (CAZy) databases (Cantarelet al ., 2009). The best BLAST hit was utilized for further analyses. The annotated KEGG Orthology (KO) genes were subsequently assigned into different functional hierarchies. The annotation results of CAZy were generated using dbCAN.

\section{6 | Statistical analysis}

QIIME software (v.1.9.1) was adopted to calculate the Alpha diversity and the Bray-Curtis distances. A K-Sample Fisher-Pitman Permutation Test was selected to analyze the differences of alpha diversity between groups. A Principal coordinate analysis (PCoA) was exhibited using QIIME2 and the ggplot2 package in $\mathrm{R}$ software based on the Bray-Curtis distance. A permutational multivariate analysis of variance (ADONIS), an analysis of similarities (ANOSIM) and a multiple response permutation procedure (MRPP) were used to examine the differences in communities. A Wilcoxon rank-sum test and a $t$-test were utilized to verify the statistical significance of differences of microbial taxa and functional gene abundance. $\mathrm{P}<0.05$ was considered statistically significant.

\section{3 | RESULTS}

\section{1 | Genomic sequencing results}

A total of 822.2 million raw reads with an average of 91.4 million per sample were obtained though metagenomic sequencing. After quality control, approximately 68.6 million clean reads per sample were generated. The clean data were assembled using MEGAHIT, and an average of 593,189, 385,194 and 187,430 scaftigs were generated in the L. secalinus rhizosphere (L) metagenome, C. praeclara rhizosphere (C) metagenome and the non-rhizosphere $(\mathrm{N})$ metagenome. A total of 8,191,664 non-redundant ORFs were obtained, and $963,114(11.8 \%)$ of them were complete ORFs. Taxonomic annotations were assigned to $66.92 \%$ of the unigenes. Across all the annotated unigenes, $99.81 \%$ were assigned to prokaryotes, including bacteria and archaea, while only $0.19 \%$ were annotated as eukaryotes.

\subsection{Composition and diversity of microbial communities}

A total of 39 prokaryotic phyla and six eukaryotic phyla were identified from all the soil samples. In particular, the dominant prokaryotic phyla with an average relative abundance [?] $1.0 \%$ were Actinobacteria $(30.7 \%)$, Proteobacteria (29.2\%), Acidobacteria (7.8\%), Chloroflexi (4.4\%), Bacteroidetes (2.4\%), Gemmatimonadates $(2.3 \%)$, Verrucomicrobia $(2.3 \%)$ and Planctomycetes $(2.1 \%)$, comprising approximately $80 \%$ of the total bacterial abundance (Figure 1a). In addition, Nocardioides, Sphingomonas, Variovorax and Bradyrhizobium were the most four abundant genera of all the samples (Figure 1b). Within the fungal community, Ascomycota, Basidiomycota and Mucoromycota were the dominant phyla, with an average relative 
abundance of $85.6 \%, 10.7 \%$ and $2.8 \%$. Ascomycota was the most abundant fungal phylum in all the samples, with the relative abundances that ranged from $83.1 \%$ (N1) to $89.2 \%$ (L2) of the fungal samples (Figure S1).

We found that the composition of microbial community differed between the samples and visualized the difference using the PCoA based on the weighted Bray-Curtis distance. The microbiota of $\mathrm{C}, \mathrm{L}$ and $\mathrm{N}$ formed three distinct clusters, which were separated along the first and second coordinate axis (Figure 1c, Figure1d). As expected, the measurement of Simpson index indicated a remarkable difference of community diversity between the C, L and N groups (Figure S2). The microbiota of C group had the highest diversity, followed by the $\mathrm{N}$ and $\mathrm{L}$ groups, indicating that the C. praeclara roots recruited more bacterial species. In particular, among the top 10 dominant bacterial phyla compared with N, the relative abundances of Actinobacteria, Proteobacteria and Bacteroidetes significantly increased, while Acidobacteria, Chloroflexi, Gemmatimonadetes, as well as those of and Candidatus Rokubacteria, significantly decreased in the C and L groups (Figure 2a). In addition, no significant changes in fungal phyla were observed between $\mathrm{C}$ and $\mathrm{N}$. However, compared with the other two groups, the relative abundances of Ascomycota and Mucoromycota significantly increased in L, while Basidiomycota significantly decreased (Figure S1b). At the genus level, compared with the N group, the relative abundance of the top 10 genera significantly increased in the $\mathrm{C}$ and $\mathrm{L}$ groups (Figure $2 \mathrm{~b}$ ), includingNocardioides, Sphingomonas, Variovorax ,Devosia, Bradyrhizobium, Aeromicrobium ,Mesorhizobium , Arthrobacter, Streptomyces andSolirubrobacter. The relative abundances of Pseudomonasand Nitrospira significantly decreased (Figure 2b). Notably, the photoautotrophic and chemoautotrophic microorganisms, such as Cyanobacteria, Chloroflexi and Nitrospirae, decreased remarkably in both C and L (Figure 2a).

\section{3 | Overall function potential of microbial communities}

Functional annotations were obtained by BLASTing against the KO database. A total of 8,028 KOs were distributed to the annotated unigenes, which were primarily involved in 23 KEGG level 2 pathways, including membrane transport, carbohydrate metabolism, signal transduction, energy metabolism, amino acid metabolism and the biodegradation and metabolism of xenobiotics among others (Figure 3a).

The PCoA based on the weighted Bray-Curtis distance revealed that the KEGG level 2 pathways of C, L and $\mathrm{N}$ formed three distinct clusters, which indicated that the functional traits differed between these three groups (Figure 3c). The rhizosphere-enriched functional pathways were involved in microbe-microbe interactions and nutrient acquisition, including the biosynthesis of other secondary metabolites, signal transduction, membrane transport and transport and catabolism. The functional traits that were markedly decreased in the rhizosphere were involved in pathways that could be related to metabolism, such as lipid metabolism, amino acid metabolism, nucleotide metabolism, carbohydrate metabolism and replication and repair (Figure S3).

Root microorganisms and plant-microbe interactions play a crucial role in plant growth and ecosystem stability. Similarly, the interactions of plant-microbes and microbe-microbes could significantly influence the composition and structure of the rhizosphere microbiome. The KOs were involved in the interactions between plant and microbe, such as bacterial secretion systems, flagella assembly, transposases, ABC-2 type transport systems, quorum sensing, bacterial chemotaxis and two-component systems, were enriched in both the $\mathrm{C}$ and $\mathrm{L}$ groups. In addition, the polysaccharide genes were also over-represented in the rhizosphere microbiome (Figure 3b and Figure 4).

\section{4 | Microbial carbohydrate-active potential}

Across all the soil samples, the most abundant carbohydrate-active genes in the CAZy database encoded glycoside hydrolases $(\mathrm{GH})$, followed by glycosyl transferases (GT), carbohydrate-binding modules (CBM), carbohydrate esterases (CE), polysaccharide lyases (PL) and auxiliary activities (AA). Both C and L had a higher abundance of genes that encoded GH, CBM, CE, PL, AA and GT (Figure S4). In particular, the over-represented CAZys in the rhizosphere soils included varied glycoside hydrolases (GH families), glycosyl transferases (GT families) and polysaccharide hydrolases (Figure 5), e.g., amylase, xylanase and cellulase, which are involved in the decomposition of root exudates and plant components. 


\section{5 | Microbial N-cycling and P-cycling potential}

The soil physicochemical analysis showed that the nutrients in the desertification soil were seriously depleted, particularly the $\mathrm{N}$ and $\mathrm{P}$ elements (Table S1). To investigate the microbial potential changes in soil N- and $\mathrm{P}$-cycling, we focused on the functional genes known to affect the transformations of $\mathrm{N}$ and $\mathrm{P}$. In particular, the KOs related to $\mathrm{N}$-cycling were enriched in $\mathrm{C}$ and $\mathrm{L}$, including denitrification (nirABD, nasAB, narBJ , and norE ), cyanase ( $\operatorname{nn} S)$ ), urease (ure $A B C)$, regulatory genes $(n a r L, g \ln B K, n \operatorname{tr} B C$ and $n a c)$ and transporters ( $n r t A B C P$ and $y f d C$ ). However, the KOs involved in nitrification ( $p m o A B C / a m o A B C$ ) and nitrogen fixation (nifU ) were remarkably reduced in $\mathrm{C}$ and $\mathrm{L}$ (Figure 6). The KOs involved in P-cycling, such as organic $\mathrm{P}$ mineralization ( $p h n P G H I J L M N$ and $p h o N$ ), as well as organic acids ( $g c d$, leuA, gltA and $g l c B$ ) that dissolve insoluble inorganic $\mathrm{P}$ and transporters (pstABCS, phnCDEKF and TC.PIT ), were enriched in $\mathrm{C}$ and L (Figure 7).

\section{4 | DISCUSSION}

\subsection{Taxonomic changes of the soil communities}

As in earlier studies, bacteria were the dominant microorganisms in the rhizosphere, while eukaryotes comprised a small portion of the sequences that are assigned to known taxa (Liu et al ., 2021). The underestimate of eukaryotic community in the rhizosphere can probably be attributed to the potential annotation bias $(\mathrm{Xu}$ et al ., 2018). In this study, we found that the diversity and composition of the microbial community from C and L were significantly different from that in $\mathrm{N}$. This finding indicated that the physicochemical properties of rhizosphere soils were profoundly influenced by plant root exudates, leading to the variation of rhizosphere microbiome from non-rhizosphere soil (Chenet al ., 2016; Edwards et al ., 2015).

In general, the particular rhizosphere microbiome recruited from the surrounding soil differs between plant species (Berendsen et al ., 2012; Lima et al ., 2015), and a plant with a specific genotype recruits particular rhizosphere microbes (Bulgarelli et al ., 2015)[24-26]. The Simpson diversity indicated that there was a significant difference between the alpha diversity of the C and L groups (Figure S2). However, the major components of the microbiome of $\mathrm{C}$ and $\mathrm{L}$ were similar, despite the fact that they are two very different species. It has been reported that different pioneer plants within a community had a similar composition in their rhizosphere bacterial community, and the community assemblage was determined by the processes of plant growth and nutrient uptake, instead of by plant species (Yeet al ., 2021). Thus, the ability to live in the sand and reproduce asexually though underground rhizomes (Kang et al ., 2017) could explain the similarities of the rhizosphere microbiome composition between C. praeclara and L. secalinus.

Although there is a substantial diversity of bacterial communities, relatively few bacterial taxa predominate in any specific soil (Xuet al ., 2018). Our results revealed that only eight of the bacterial phyla comprised nearly $80 \%$ of the total bacterial abundance, including Actinobacteria, Proteobacteria, Acidobacteria and Chloroflexi among others (Figure 1a). These bacteria have also been reported to be major taxa in other plant rhizospheres(Enzong et al., 2019; J. Yu et al., 2020). Analyses of differential abundances revealed that the bacterial taxa that are members of Proteobacteria, includingSphingomonas, Variovorax , Devosia ,Bradyrhizobium and Mesorhizobium, and Actinobacteria, including Nocardioides , Aeromicrobium ,Arthrobacter , Streptomyces and Solirubrobacter, were significantly enriched in the rhizospheres of both C. praeclara and L. secalinus . These bacteria have been reported to play an essential role in the decomposition of aromatic compounds (Ju \& Parales, 2010; Liu et al ., 2021) and the production of 1-aminocyclopropane-1-carboxylate (ACC) deaminase (Jiang, 2012). Plants usually release aromatic compounds to defend themselves against plant pathogens (Xu et al ., 2018). ACC deaminase can degrade the precursor of ethylene (ACC), thus, reducing the level of ethylene concentration in the rhizosphere, which is conducive to plant growth under drought stress (Jiang, 2012). In addition, some taxa of these rhizosphere bacteria have been found to produce plant hormones, assist nutrients uptake, promote root development, and inhibit plant diseases (Philippe et al ., 2017; Verbon \& Liberman, 2016). The enrichment of these bacteria may be attributed to their abilities to grow rapidly and utilize multiple carbon and nitrogen sources in the rhizosphere. In contrast, some photoautotrophic and chemoautotrophic microorganisms, such as Cyanobacteria, Chloroflexi and Nitrospirae, 
were markedly reduced in N (Figure 2a), which was consistent with the fact that plant root exudates provide sufficient and varied nutrients for microorganisms (Bai et al ., 2015).

\subsection{Functional changes of the soil communities}

Nutrition in the surrounding environment is likely to be an important factor that would affect the microbiome assemblage and lead to the differences in metabolic functions (Xu et al ., 2018). The analysis of soil physicochemical properties showed that the nutrition of desertified soil was very poor (Table S1). Therefore, plant root-derived compounds are probably major sources of nutrition for microorganisms (Liu et al ., 2021). Consistent with this, ABC transporters that are used to absorb and transport root-derived nutrients, such as amino acids, monosaccharides, polysaccharides, vitamins, lipids and minerals, were enriched in both the $\mathrm{C}$ and L groups (Figure 3b). As observed in previous studies (Bulgarelli et al ., 2015; Ofek-Lalzar et al ., 2013), the functions related to amino acid biosynthesis and metabolism, fatty acid biosynthesis and energy metabolism were over-represented in the $\mathrm{N}$ group, which is consistent with the fact that rhizosphere microbes can acquire varieties of simple nitrogen and carbon nutrients from root secretions, and therefore would not need to invest in their biosynthesis (Liu et al ., 2021). Similarly, the pathways associated with carbon fixation in prokaryotes were under-represented in both $\mathrm{C}$ and $\mathrm{L}$, which is consistent with the absence of autotrophic microorganisms in the rhizosphere. Notably, the KOs related to polysaccharide biosynthesis were enriched in $\mathrm{C}$ and $\mathrm{L}$ (Figure 4). It has been reported that polysaccharides could improve the aggregation and water-holding capacity of the soil (Deka et al ., 2018; Sahaet al ., 2020). Therefore, some rhizosphere microorganisms can maintain moisture in the rhizosphere soil by synthesizing and secreting polysaccharides, which enhances the tolerance of plants to drought and water fluctuation, and improves the dissolution of minerals and the absorption of nutrients. In addition, the enrichment of genes associated with bacterial secretion systems, chemotaxis, flagella assembly, quorum sensing and nutrition transporters in C and L, suggests that more intense plant-microbes and microbe-microbes interactions occur in the rhizosphere (Figure 3b and Figure 4).

\section{3 | Carbohydrate-active potential changes of the soil communities}

Carbohydrates are the primary sources of $\mathrm{C}$ and energy for microorganisms. Samples of $\mathrm{C}$ and $\mathrm{L}$ contained a higher abundance of CAZy genes than the N samples (Figure S4b). These genes encode multiple glycosyl hydrolases $(\mathrm{GHs})$, polysaccharide hydrolases and auxiliary enzymes that together participate in the depolymerization and utilization of recalcitrant compounds derived from plants and exudations from the roots, such as cellulose, lignin, starch and other polysaccharides (Perez-Mon et al ., 2021). These findings indicated that microorganisms can obtain and use multiple carbon sources in the rhizosphere. Up to approximately $40 \%$ of the photosynthates of plants are secreted into the rhizosphere (Bais et al ., 2006). This is a mutually beneficial relationship in which plants provide the nutrients necessary for the survival and reproduction of rhizosphere microorganisms, which in turn will promote plant health and growth.

\subsection{N-cycling and P-cycling potential changes of the soil communities}

$\mathrm{N}$ is an essential element of all life and the primary nutrient that restricts the growth of plants in terrestrial ecosystems (Kuyperset al ., 2018). Microbes promote the transformation of $\mathrm{N}$ by catalyzing a series of reactions, primarily including assimilation, ammonification, nitrification, denitrification, anammox and nitrogen fixation (Kuypers et al ., 2018). A series of enzymes that participate in the transformation of N, such as assimilatory nitrate reductase, assimilatory nitrate reductase, cyanase along with urease, and nitrate/nitrite transporters and nitrogen regulators exhibit a higher abundance in $\mathrm{C}$ and L, suggesting that there is an enhanced amount of N-cycling that occurs in the rhizosphere soil (Figure 6). In contrast, many chemoautotrophic bacteria, such as Nitrospira, can oxidize ammonia to hydroxylamine using methane/ammonia monooxygenase (Hooper et al ., 1997). The marked reduction of genes that encode methane/ammonia monooxygenase could be explained by the reduction of chemoautotrophic microorganisms. The NifU protein is required for the full activation of the metalloenzyme nitrogenase, the catalytic component of biological nitrogen fixation, and a high abundance of thenifU gene was detected in all the samples. Strangely, the NifH gene is usually used as a marker to detect nitrogen-fixing bacteria in the environment (Zehr et al ., 2003), 
but few of the unigenes were assigned to it in all the samples. This could be explained by the fact that the nifH gene merely occurs in specific bacterial taxa, which comprise a tiny fraction of the whole microbial community in natural ecosystems (Henry et al ., 2006) and that the application of shotgun metagenome sequencing has limitations to analyze gene families that are present at low abundance (Zhou et al ., 2015).

$\mathrm{P}$ is thought to be an important ecological and evolutionary factor and predominates over all the other elements, including C and N (Elser, 2012). However, plants can release extracellular phosphatases to capture and recycle the organic P lost from roots or to allow greater access to soil organic P. An experiment was conducted to evaluate the rhizosphere soil after plant growth, and the results indicated a marked reduction of phytase-labile P, but it did not differ significantly compared with the control soils that lacked plants (Richardson et al ., 2009). In addition, there is evidence that microbial enzymes have a higher efficiency for the release of $\mathrm{P}$ (Tarafdar et al ., 2015). This suggests that microbes are in fact key drivers to enhance the capacity of plants to acquire $\mathrm{P}$ from the soil. Microorganisms can promote $\mathrm{P}$ cycling through various mechanisms, and the primary mechanisms are the mineralization of organic $\mathrm{P}$ and solubilization of inorganic P. Soil microorganisms can produce a type of phosphatase to utilize various forms of organic $\mathrm{P}$ in the soil, including phytate and myoinositol hexakisphosphate along with other isomers and lower-order derivatives (Lim et al ., 2007). Similarly, many microorganisms can solubilize inorganic P by releasing organic acids that primarily contain citrate, gluconate, oxalate, and succinate (Khan et al ., 2007). Plant inoculation experiments using P-mineralizing and P-solubilizing microorganisms isolated from the soil indicated that microbes could enhance the utilization of $\mathrm{P}$ and improve the growth of plants. The enrichment of KOs involved in phosphatase ( $p h o N, p h n J$ and $p h n N)$, organic acids ( $g c d$ and gltA ), $\mathrm{P}$ regulatory proteins $(p h o B$ and $p h o R)$ and $\mathrm{P}$ transporters (pstBand pstS ) in $\mathrm{C}$ and $\mathrm{L}$ indicate a higher activity of $\mathrm{P}$ cycling in the rhizosphere soil (Figure 7).

\section{5 | CONCLUSIONS}

Our study on the microbiome metagenomes underlies the composition and remarkable difference in the taxonomic and functional characteristics between the rhizosphere and non-rhizosphere soils of $C$. praeclaraand L. secalinus . Actinobacteria, Proteobacteria, Acidobacteria and Chloroflexi were generally the dominant bacterial phyla across all the samples, while the relative abundance of autotrophic microorganisms decreased in the rhizosphere. The rhizosphere microbes exhibit complex microbial interactions and have a higher potential to transform $\mathrm{N}$ and $\mathrm{P}$, which promote the growth of plants and improve the properties of soil. The interactions among rhizosphere soil microbial communities along withCarex praeclara and Leymus secalinus presented here provide a valuable reference for the further utilization of such microbes to improve pioneer plant growth and restore extremely degraded grassland ecosystems.

\section{ACKNOWLEDGMENTS}

The authors gratefully acknowledge the sequencing supports by the MAGIGENE Co., Ltd. This work was supported by the Second Tibetan Plateau Scientific Expedition and Research Program (2019QZKK0404).

\section{CONFLICT OF INTEREST}

The authors declare no conflict of interest.

\section{DATA AVAILABILITY STATEMENT}

The data that support the findings of this study are available from the corresponding author upon reasonable request. The raw sequencing reads has been deposited in the NCBI Bioproject database with the accession number PRJNA751553.

\section{SUPPORTING INFORMATION}

Additional supporting information may be found online in the Supporting Information section at the end of this article.

\section{REFERENCES}


Bai, Y., Mueller, D. B., Srinivas, G., Garrido-Oter, R., Potthoff, E., Rott, M., \& Remus-Emsermann, M. (2015). Functional overlap of the Arabidopsis leaf and root microbiota. Nature, 528 , 364-369.

https://doi.org/10.1038/nature16192

Bais, H. P., Weir, T. L., Perry, L. G., Gilroy, S., \& Vivanco, J. M. (2006). The role of root exudates in rhizosphere interactions with plants and other organisms. Annual Review of Plant Biology, 57, 233-266. https://doi.org/10.1146/annurev.arplant.57.032905.105159

Bashan, Y., \& De-Bashan, L. E. (2010). How the plant growth-promoting bacterium Azospirillum promotes plant growth - a critical assessment.Advances in Agronomy, 108 , 77-136.

https://doi.org/10.1016/S0065-2113(10)08002-8

Berendsen, R. L., Pieterse, C., \& Bakker, P. (2012). The rhizosphere microbiome and plant health. Trends in Plant Science, 17, 478-486. https://doi.org/10.1016/j.tplants.2012.04.001

Bhattacharyya, P. N., \& Jha, D. K. (2012). Plant growth-promoting rhizobacteria (PGPR): emergence in agriculture. World Journal of Microbiology 83 Biotechnology, 28 , 1327-1350.

https://doi.org/10.1007/s11274-011-0979-9

Buchfink, B., Xie, C., \& Huson, D. H. (2015). Fast and sensitive protein alignment using DIAMOND. Nature Methods, 12 , 59-60.

https://doi.org/10.1038/nmeth.3176

Bulgarelli, D., Garrido-Oter, R., Munch, P., Weiman, A., Dr?Ge, J., Pan, Y., \& Schulze-Lefert, P. (2015). Structure and Function of the Bacterial Root Microbiota in Wild and Domesticated Barley. Cell Host $\mathcal{E}^{3}$ Microbe, 17 , 392-403.

https://doi.org/10.1016/j.chom.2015.01.011

Cantarel, B. L., Coutinho, P. M., Rancurel, C., Bernard, T., Lombard, V., \& Henrissat, B. (2009). The Carbohydrate-Active EnZymes database $(\mathrm{CAZy})$ : an expert resource for glycogenomics. Nucleic Acids Research, 37 , D233-D238. https://doi.org/10.1093/nar/gkn663

Chen, L., Brookes, P. C., Xu, J., Zhang, J., Zhang, C., Zhou, X., \& Luo, Y. (2016). Structural and functional differentiation of the root-associated bacterial microbiomes of perennial ryegrass. Soil Biology $\mathscr{E}$ Biochemistry, 98 , 1-10.

https://doi.org/10.1016/j.soilbio.2016.04.004

Deka, P., Goswami, G., Das, P., Gautom, T., Chowdhury, N., Boro, R. C., \& Barooah, M. (2018). Bacterial exopolysaccharide promotes acid tolerance in Bacillus amyloliquefaciens and improves soil aggregation. Molecular Biology Reports .

https://doi.org/10.1007/s11033-018-4566-0

Deng, Q., Wan, L., Li, X., Cao, X., Zhou, Y., \& Song, C. (2020). Metagenomic evidence reveals denitrifying community diversity rather than abundance drives nitrate removal in stormwater biofilters amended with different organic and inorganic electron donors. Chemosphere, 257, 127269. https://doi.org/10.1016/j.chemosphere.2020.127269

Edwards, J., Johnson, C., Santos-Medellin, C., Lurie, E., \& Sundaresan, V. (2015). Structure, variation, and assembly of the root-associated microbiomes of rice. Proceedings of the National Academy of Sciences, 112. https://doi.org/10.1073/pnas.1414592112

Elser, J. J. (2012). Phosphorus: a limiting nutrient for humanity? Current Opinion in Biotechnology, 23 . https://doi.org/10.1016/j.copbio.2012.03.001 
Fang, W., Yongtao, H., Gang, F., Ben, N., Haorui, Z., Meng, L., \& Xianzhou, Z. (2020). Effects of Enclosure on Plant and Soil Nutrients in Different Types of Alpine Grassland. Journal of Resources and Ecology, 11 .

https://doi.org/10.5814/j.issn.1674-764x.2020.03.006

Guo, Y., Xu, T., Cheng, J., Wei, G., \& Lin, Y. (2021). Above-and belowground biodiversity drives soil multifunctionality along a long-term grassland restoration chronosequence. The Science of the Total Environment, 772, 145010-145010.

https://doi.org/10.1016/j.scitotenv.2021.145010

Henry, S., Bru, D., Stres, B., Hallet, S., \& Philippot, L. (2006). Quantitative Detection of the nosZ Gene, Encoding Nitrous Oxide Reductase, and Comparison of the Abundances of 16S rRNA, narG, nirK, and nosZ Genes in Soils. Applied \& Environmental Microbiology, 72 , 5181-5189. https://doi.org/10.1128/AEM.00231-06

Hooper, A. B., Vannelli, T., Bergmann, D. J., \& Arciero, D. M. (1997). Enzymology of the oxidation of ammonia to nitrite by bacteria. Antonie van Leeuwenhoek, 71 , 59-67.

https://doi.org/10.1023/A:1000133919203

Jiang, F. (2012). Multiple impacts of the plant growth-promoting rhizobacterium Variovorax paradoxus 5C-2 on nutrient and ABA relations of Pisum sativum. Journal of Experimental Botany, 63 , 6421-6430.

https://doi.org/10.1093/jxb/ers301

Ju, K. S., \& Parales, R. E. (2010). Nitroaromatic Compounds, from Synthesis to Biodegradation. Microbiology 83 Molecular Biology Reviews Mmbr, 74 , 250. https://doi.org/10.1128/MMBR.00006-10

Kanehisa, M., \& Goto, S. (2000). KEGG: kyoto encyclopedia of genes and genomes. Nucleic acids research, $28,27-30$.

https://doi.org/10.1093/nar/27.1.29

Kang, J., Zhao, W., \& Zhao, M. (2017). Remediation of blowouts by clonal plants in Maqu degraded alpine grasslands of northwest China. Journal of plant research, 130 , 291-299.

https://doi.org/10.1007/s10265-016-0884-2

Kang, J. J., Zhao, W. Z., \& Zhao, M. (2017). Remediation of blowouts by clonal plants in Maqu degraded alpine grasslands of northwest China. Journal of Plant Research, 130 , 1-9.

https://doi.org/10.1007/s10265-016-0884-2

Khan, M. S., Zaidi, A., \& Wani, P. A. (2007). Role of phosphate-solubilizing microorganisms in sustainable agriculture - A review. Agronomy for Sustainable Development, 27 , 29-43.

https://doi.org/10.1051/agro:2006011

Kuypers, M. M. M., Marchant, H. K., \& Kartal, B. (2018). The microbial nitrogen-cycling network. Nat Rev Microbiol, 16 , 263-276.

https://doi.org/10.1038/nrmicro.2018.9

Lim, B. L., Yeung, P., Cheng, C., \& Hill, J. E. (2007). Distribution and diversity of phytate-mineralizing bacteria. The ISME Journal, 1 , 321-330. https://doi.org/10.1038/ismej.2007.40

Lima, A. B., Cannavan, F. S., Navarrete, A. A., Teixeira, W. G., Kuramae, E. E., \& Tsai, S. M. (2015). Amazonian Dark Earth and Plant Species from the Amazon Region Contribute to Shape Rhizosphere Bacterial Communities. Microbial Ecology, 69 , 855-866.

https://doi.org/10.1007/s00248-014-0472-8 
Liu, G., Chen, L., Deng, Q., Shi, X., Lock, T. R., Kallenbach, R. L., \& Yuan, Z. (2020). Vertical changes in bacterial community composition down to a depth of $20 \mathrm{~m}$ on the degraded Loess Plateau in China.Land Degradation 63 Development, $31,1300-1313$.

https://doi.org/10.1002/ldr.3542

Liu, H., Lin, H., Song, B., Sun, X., Xu, R., Kong, T., \& Sun, W. (2021). Stable-isotope probing coupled with high-throughput sequencing reveals bacterial taxa capable of degrading aniline at three contaminated sites with contrasting pH. Science of The Total Environment . https://doi.org/10.1016/j.scitotenv.2020.144807

Liu, J., He, X., Sun, J., \& Ma, Y. (2021). A Degeneration Gradient of Poplar Trees Contributes to the Taxonomic, Functional, and Resistome Diversity of Bacterial Communities in Rhizosphere Soils. International Journal of Molecular Sciences, 22, 3438.

https://doi.org/10.3390/ijms22073438

Mendes, L. W., Kuramae, E. E., Navarrete, A. A., Van Veen, J. A., \& Tsai, S. M. (2014). Taxonomical and functional microbial community selection in soybean rhizosphere. The ISME Journal, 8 , 1577-1587.

https://doi.org/10.1038/ismej.2014.17

Ofek-Lalzar, M., Sela, N., Goldman-Voronov, M., Green, S. J., Hadar, Y., \& Minz, D. (2013). Niche and host-associated functional signatures of the root surface microbiome. Nature Communications, 5 , 4950.

https://doi.org/10.1038/ncomms5950

Oh, J., Byrd, A. L., Deming, C., Conlan, S., Kong, H. H., \& Segre, J. A. (2014). Biogeography and individuality shape function in the human skin metagenome. Nature, 514, 59-64.

https://doi.org/10.1038/nature13786

Perez-Mon, C., Qi, W., Vikram, S., Frossard, A., Makhalanyane, T., Cowan, D., \& Frey, B. (2021). Shotgun metagenomics reveals distinct functional diversity and metabolic capabilities between 12 000-year-old permafrost and active layers on Muot da Barba Peider (Swiss Alps).Microbial Genomics, 7 .

https://doi.org/10.1099/mgen.0.000558

Philippe, Lemanceau, Manuel, Blouin, Daniel, Muller, \& Moenne-Loccoz. (2017). Let the Core Microbiota Be Functional. Trends in Plant Science . https://doi.org/10.1016/j.tplants.2017.04.008

Richardson, A. E., Hocking, P. J., Simpson, R. J., \& George, T. S. (2009). Plant mechanisms to optimise access to soil phosphorus. Crop \& Pasture Science, 60 , 124-143.

https://doi.org/10.1071/CP07125

Rincon-Molina, C. I., Martinez-Romero, E., Ruiz-Valdiviezo, V. M., Velazquez, E., Ruiz-Lau, N., RogelHernandez, M. A., \& Rincon-Rosales, R. (2020). Plant growth-promoting potential of bacteria associated to pioneer plants from an active volcanic site of Chiapas (Mexico).Applied Soil Ecology, 146 .

https://doi.org/10.1016/j.apsoil.2019.103390

Saha, I., Datta, S., \& Biswas, D. (2020). Exploring the Role of Bacterial Extracellular Polymeric Substances for Sustainable Development in Agriculture. Current Microbiology, 77 .

https://doi.org/10.1007/s00284-020-02169-y

Tarafdar, J. C., Yadav, R. S., \& Meena, S. C. (2015). Comparative efficiency of acid phosphatase originated from plant and fungal sources. Journal of Plant Nutrition and Soil Science = Zeitschrift fuer Pflanzenernaehrung und Bodenkunde, 164, 279-282.

https://doi.org/10.1002/1522-2624(200106)164:3 
Verbon, E. H., \& Liberman, L. M. (2016). Beneficial Microbes Affect Endogenous Mechanisms Controlling Root Development. Trends in Plant Science, 218.

https://doi.org/10.1016/j.tplants.2016.01.013

Walters, W. A., Jin, Z., Youngblut, N., Wallace, J. G., Sutter, J., Zhang, W., \& Shi, Q. (2018). Large-scale replicated field study of maize rhizosphere identifies heritable microbes. Proceedings of the National Academy of Sciences, 115 , 7368-7373.

https://doi.org/10.1073/pnas.1800918115

Xu, J., Zhang, Y., Zhang, P., Trivedi, P., Riera, N., Wang, Y., \& Coletta-Filho, H. D. (2018). The structure and function of the global citrus rhizosphere microbiome. Nature Communications, 9 , 1-10.

https://doi.org/10.1038/s41467-018-07343-2

Ye, F., Wang, X., Wang, Y., Wu, S., Wu, J., \& Hong, Y. (2021). Different pioneer plant species have similar rhizosphere microbial communities. Plant and Soil, 464, 165-181.

https://doi.org/10.1007/s11104-021-04952-7

Yu, C., Zhang, X., Zhang, J., Li, S., Song, C., Fang, Y., \& Wu, J. (2016). Grazing exclusion to recover degraded alpine pastures needs scientific assessments across the northern Tibetan Plateau.Sustainability, 8 , 1162. https://doi.org/10.3390/su8111162

Yu, J., Liu, F., Tripathi, B. M., \& Steinberger, Y. (2020). Changes in the composition of soil bacterial and fungal communities after revegetation with Caragana microphylla in a desertified semiarid grassland. Journal of Arid Environments, 182 .

https://doi.org/10.1016/j.jaridenv.2020.104262

Zehr, J. P., Jenkins, B. D., Short, S. M., \& Steward, G. F. (2003). Nitrogenase gene diversity and microbial community structure: A cross-system comparison. Environmental Microbiology, 5 , 539-554.

https://doi.org/10.1046/j.1462-2920.2003.00451.x

Zhang, J., Liu, Y.-X., Zhang, N., Hu, B., Jin, T., Xu, H., \& Guo, X. (2019). NRT1. 1B is associated with root microbiota composition and nitrogen use in field-grown rice. Nature Biotechnology, 37, 676-684. https://doi.org/10.1038/s41587-019-0104-4

Zhang, Y. L., Chen, L. J., Chen, X. H., Tan, M. L., Duan, Z. H., Wu, Z. J., \& Fan, X. H. (2015). Response of soil enzyme activity to long-term restoration of desertified land. Catena, 133 , 64-70.

https://doi.org/10.1016/j.catena.2015.04.012

Zhou, J., He, Z., Yang, Y., Ye, D., \& Alvarez-Cohen, L. (2015). High-Throughput Metagenomic Technologies for Complex Microbial Community Analysis: Open and Closed Formats. mBio, 6 .

https://doi.org/10.1128/mBio.02288-14

Figures 

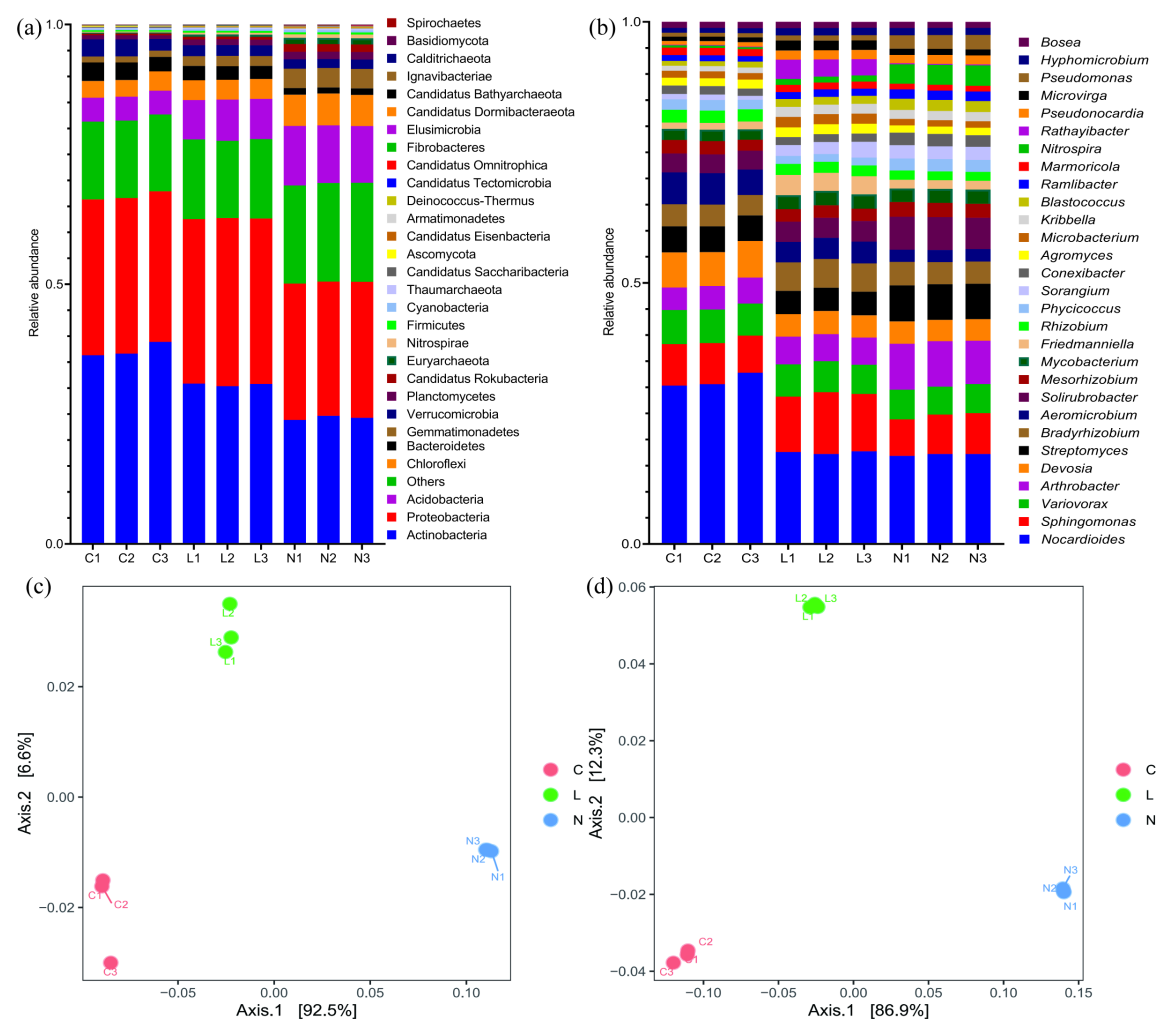

Figure 1
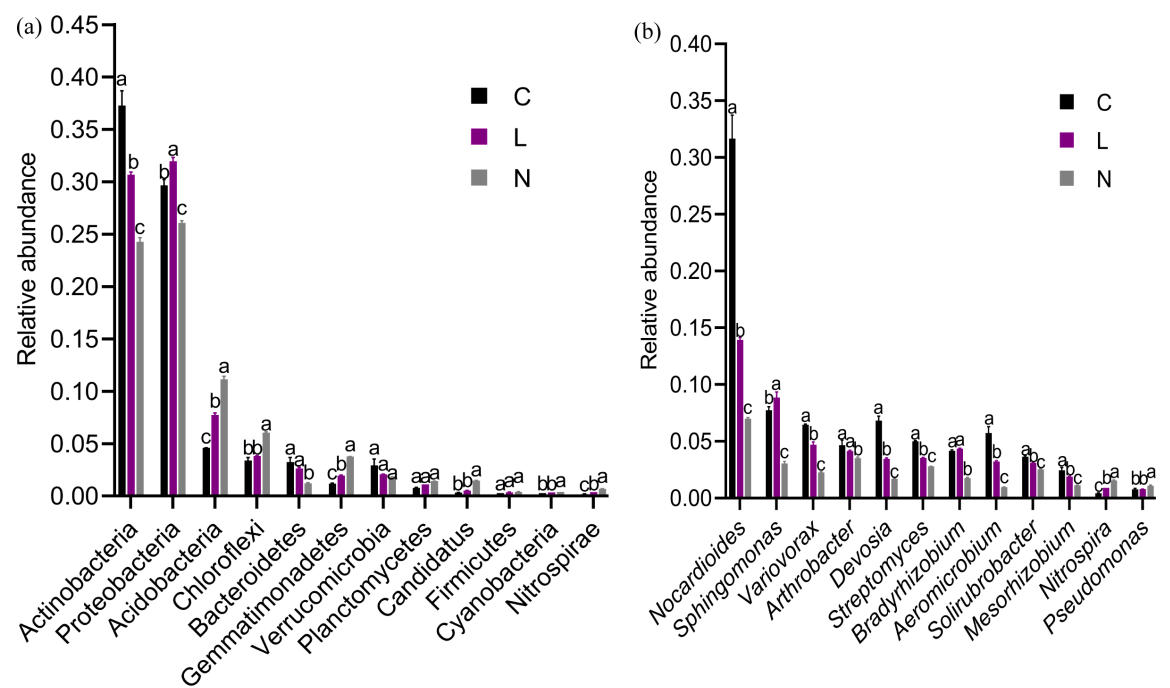

Figure 2 

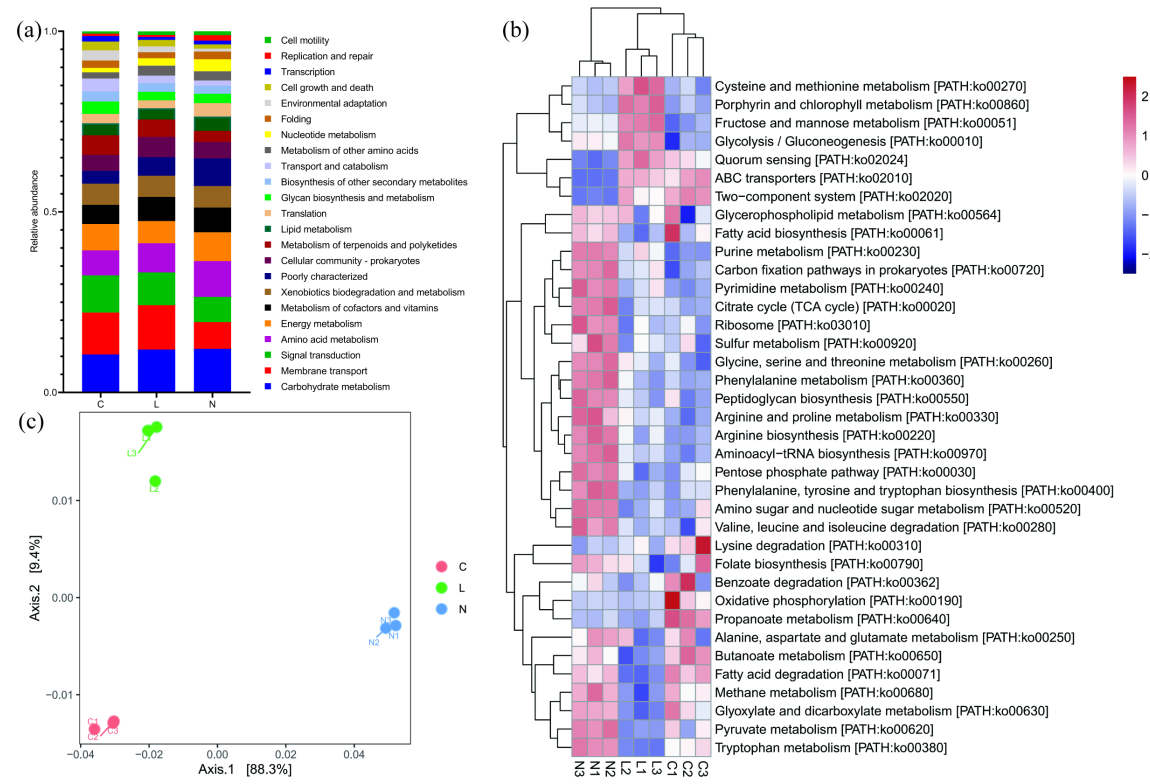

Figure 3 


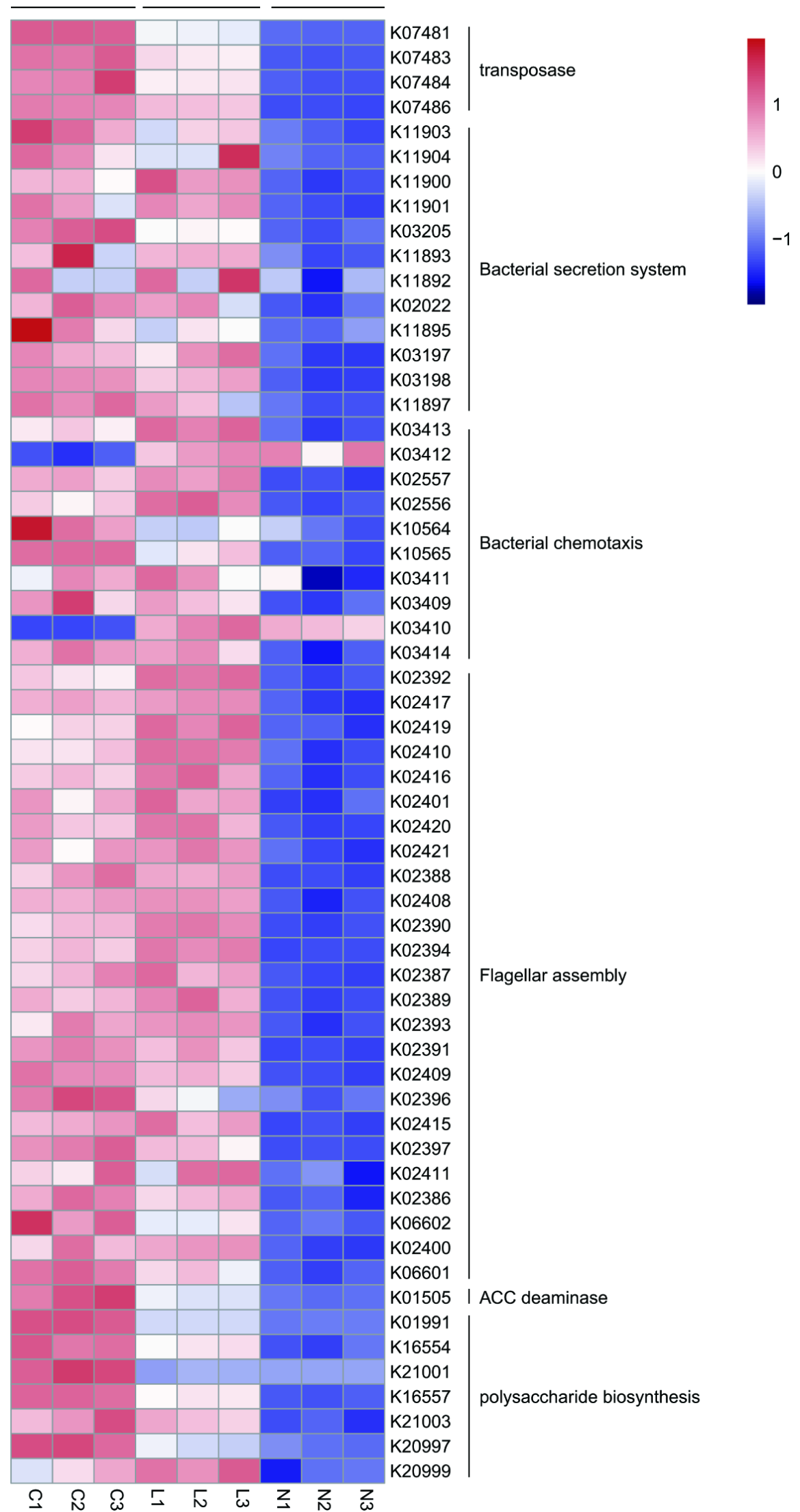


Figure 4 


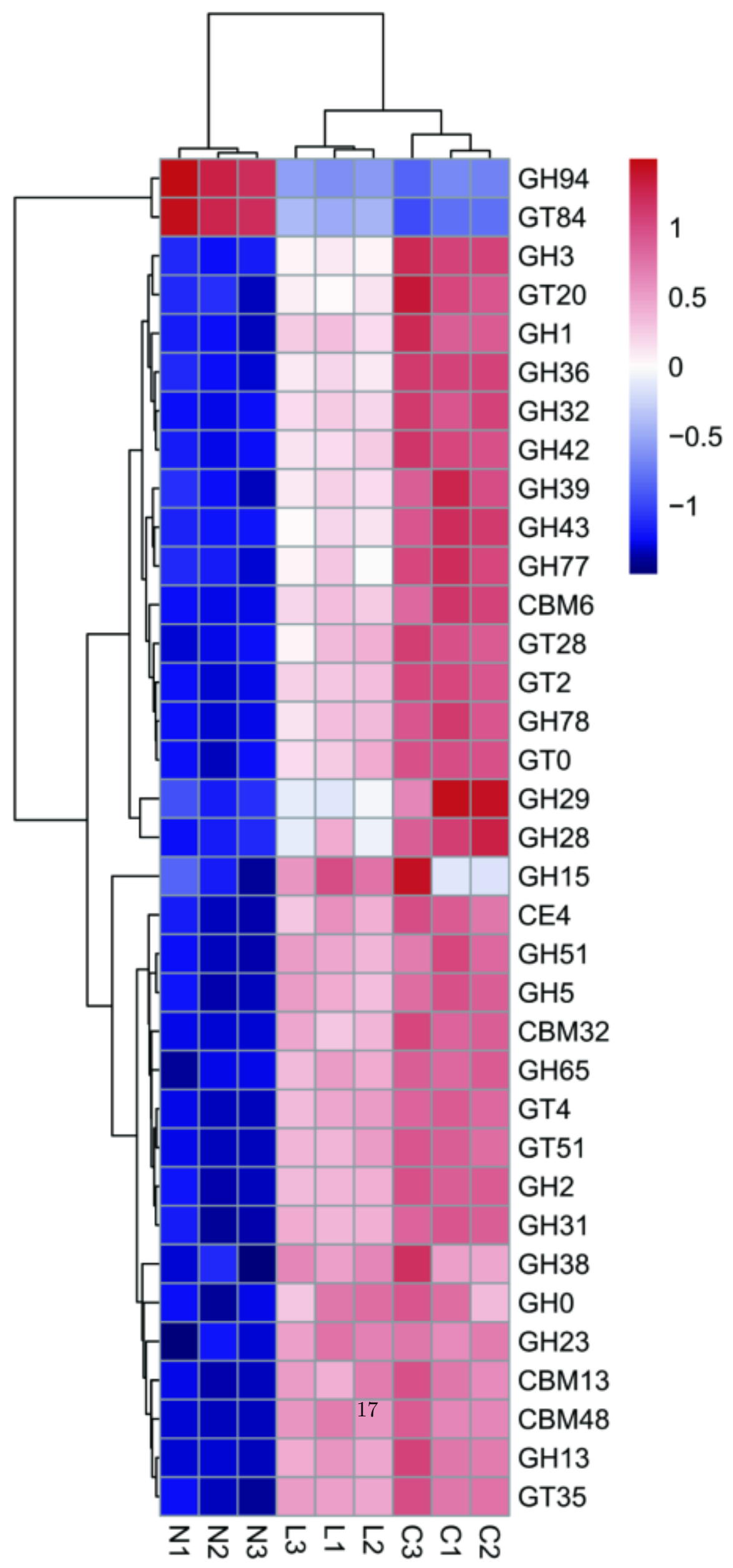


Figure 5

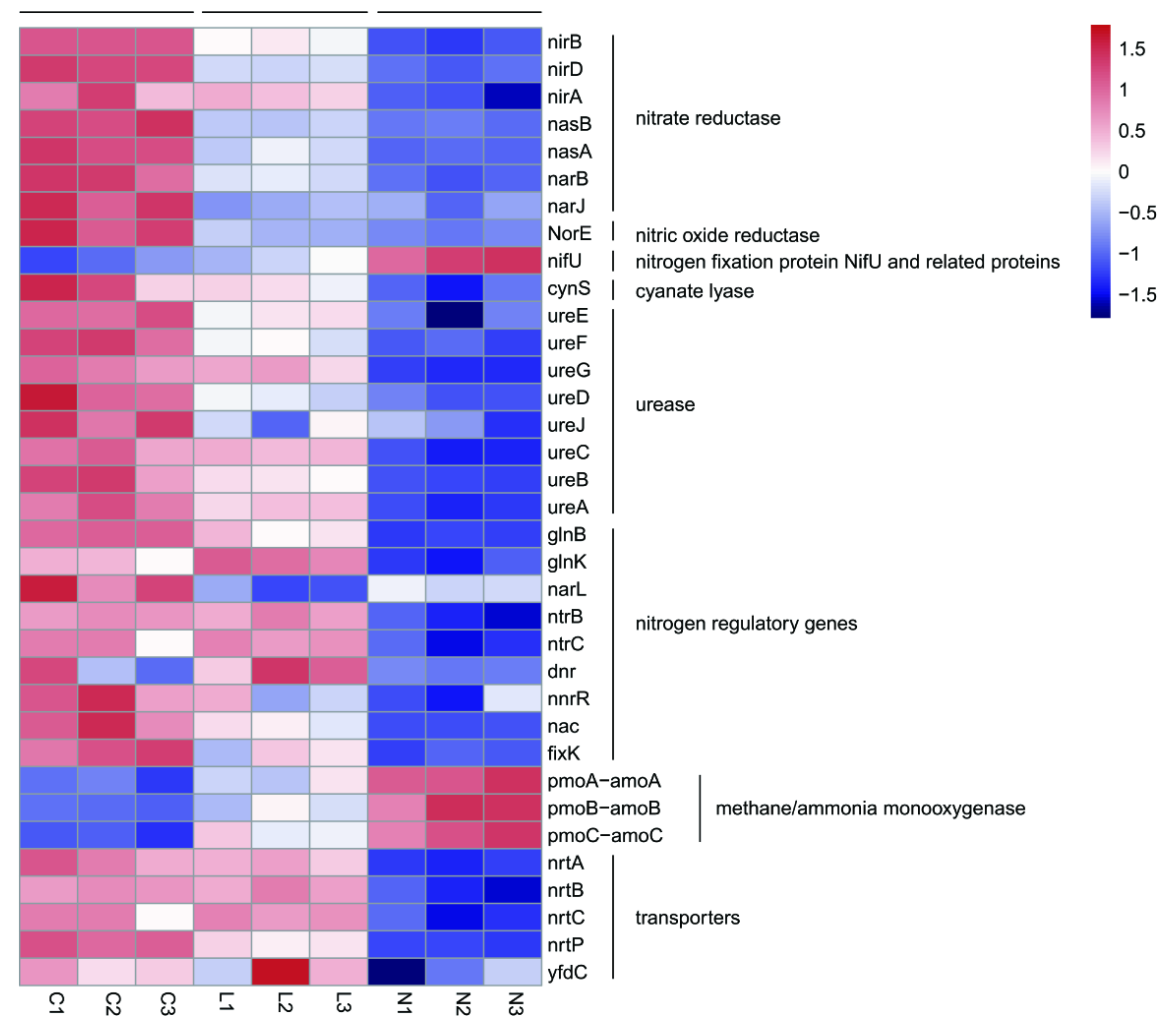

Figure 6 


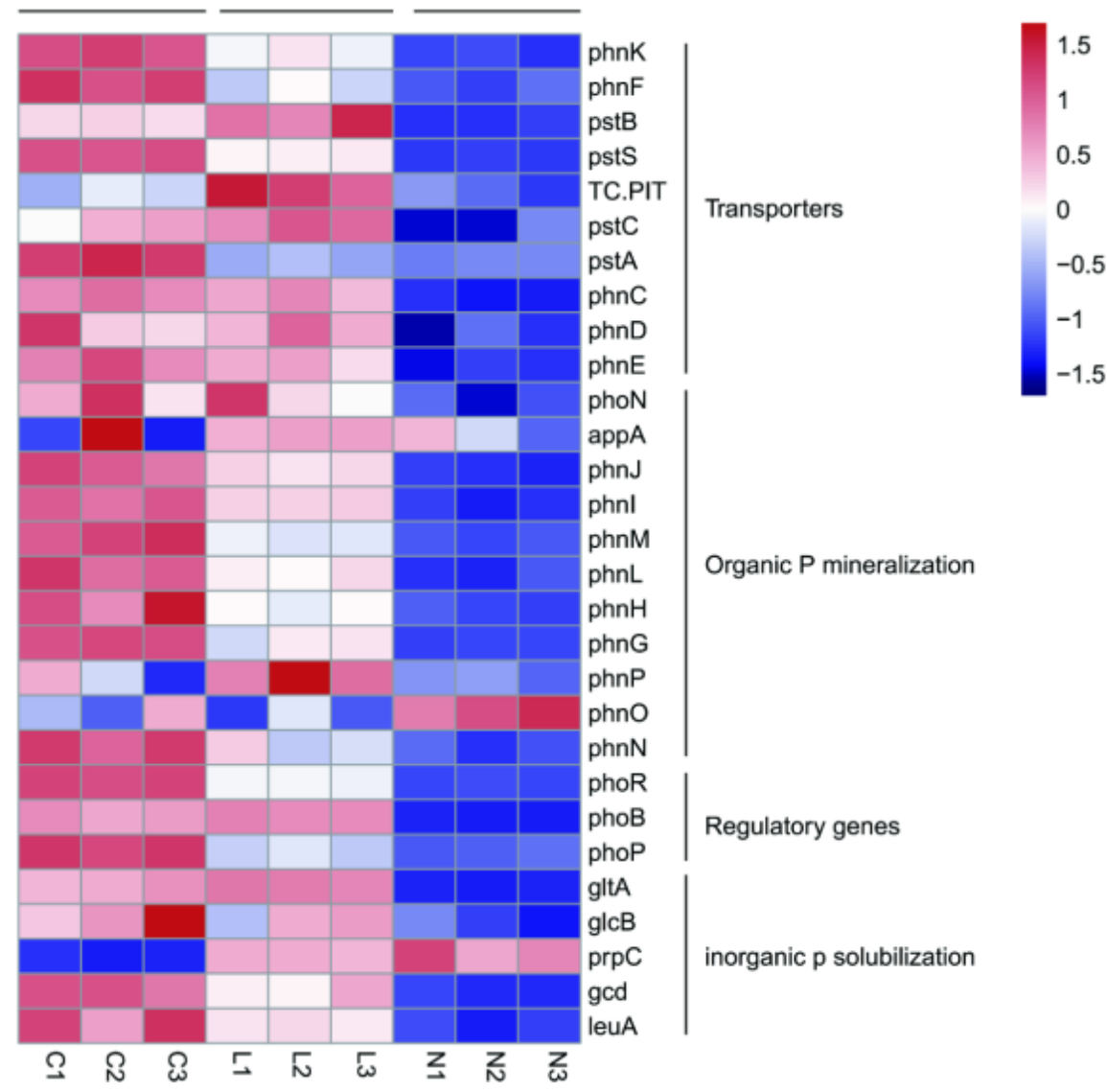

\section{Figure 7}

\section{Figure legends}

Figure 1. A comparison of bacterial communities at different taxonomic levels. Relative abundance of the bacterial phyla (a) and genera (b); A PCOA analysis of bacterial phyla (c) and genera (d) based on the weighted Bray-Curtis distance. C, rhizosphere soil of C. praeclara ; L, rhizosphere soil of L. secalinus ; N, non-rhizosphere soil.

Figure 2. Changes in the abundance of soil bacterial dominant phyla (a) and genera (b). C, rhizosphere soil of C. praeclara ; L, rhizosphere soil of L. secalinus ; N, non-rhizosphere soil.

Figure 3. A comparative analysis of functional pathway (a), and PCOA analysis (b) of the rhizosphere and non-rhizosphere soil microbiome at Kyoto Encyclopedia of Genes and Genomes (KEGG) level 2. A heatmap analysis of the top 35 most abundant KEGG level 3 pathways (c). C, rhizosphere soil of C. praeclara ; L, rhizosphere soil of L. secalinus ; N, non-rhizosphere soil.

Figure 4. A heatmap analysis of rhizosphere KOs involved in the interactions between microbe-microbe and microbe-plant. C, rhizosphere soil of C. praeclara ; L, rhizosphere soil of L. secalinus ; N, non-rhizosphere soil.

Figure 5. A heatmap analysis of the top 35 most abundant families of carbohydrate-active enzymes. C, rhizosphere soil of C. praeclara ; L, rhizosphere soil of L. secalinus ; N, non-rhizosphere soil.

Figure 6. The relative abundances of genes associated with nitrogen transformation in the soil microbiome. C, rhizosphere soil of C. praeclara ; L, rhizosphere soil of L. secalinus ; N, non-rhizosphere soil. 
Figure 7. The relative abundances of genes associated with phosphorus transformation in the soil microbiome. C, rhizosphere soil ofC. praeclara ; L, rhizosphere soil of L. secalinus ; N, non-rhizosphere soil.

\section{Supplementary Materials}

(a)

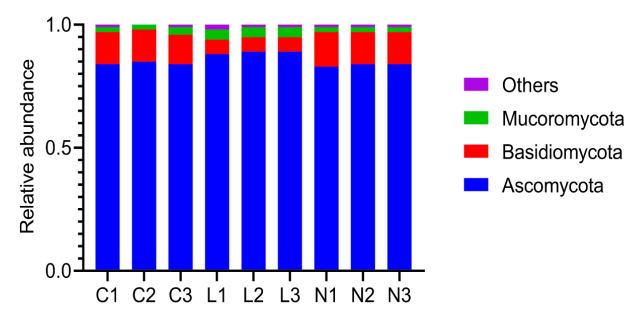

(b)

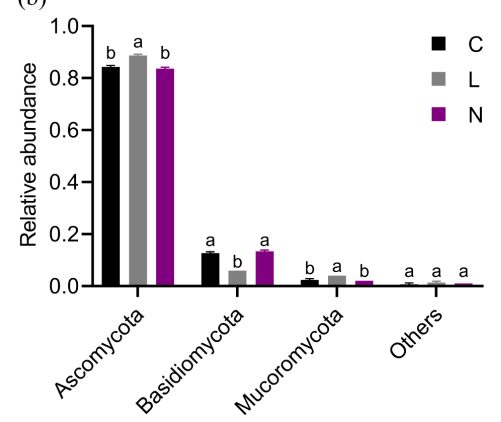

Figure S1. Comparative analyses of the relative abundance of fungal phyla. C, rhizosphere soil of $C$. praeclara ; L, rhizosphere soil of L. secalinus ; N, non-rhizosphere soil.

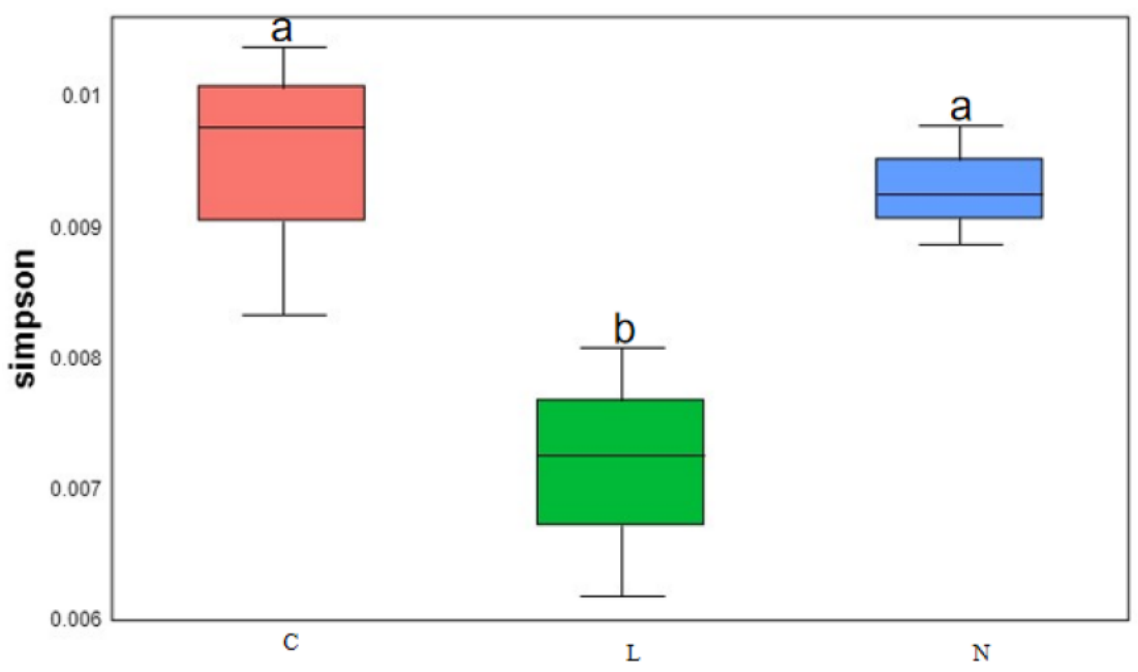

Figure S2. Alpha diversity comparison between samples from the rhizosphere soil and non-rhizosphere soil based on the Simpson index; the center value represents the median of Simpson index. C, rhizosphere soil of $C$. praeclara ; L, rhizosphere soil of L. secalinus ; N, non-rhizosphere soil. 


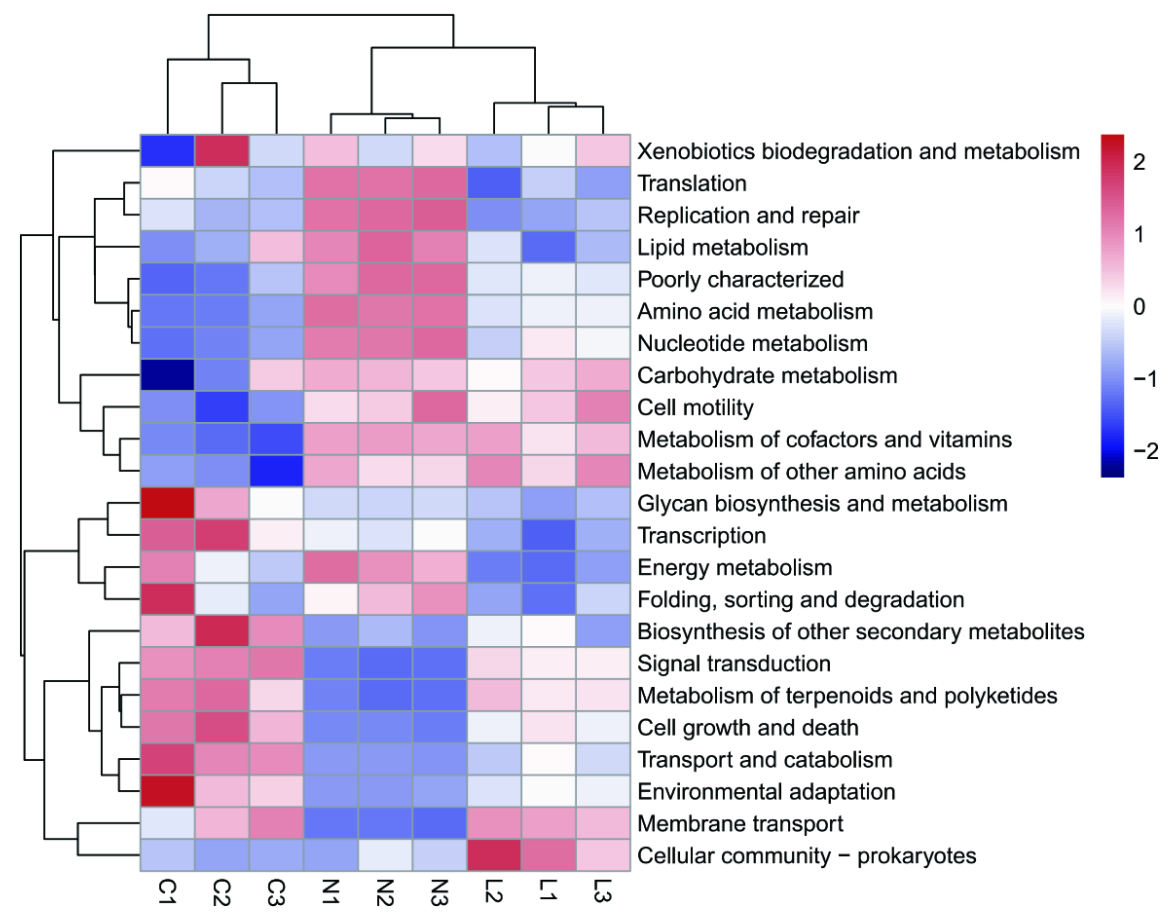

Figure S3. A heatmap analysis of the KEGG level 2 pathways. C, rhizosphere soil of C. praeclara ; L, rhizosphere soil of L. secalinus ; N, non-rhizosphere soil.
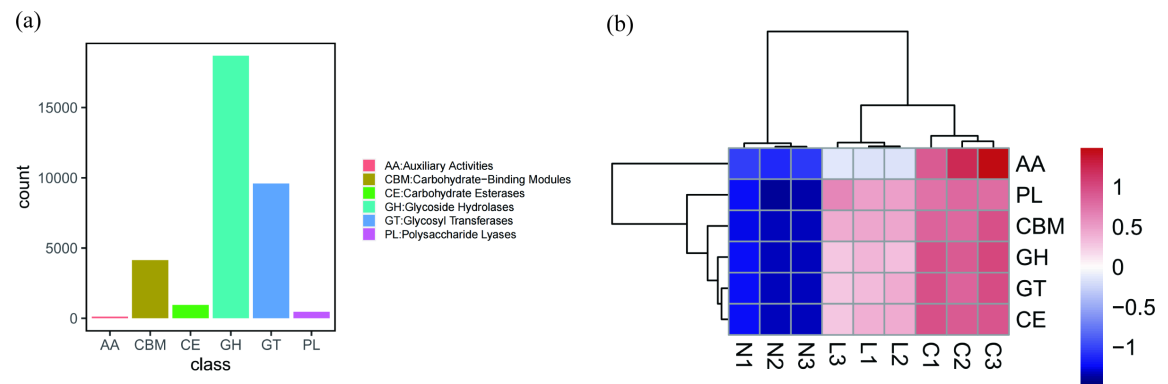

Figure S4. Gene numbers of different carbohydrate-active enzymes classes of annotation results (a), and a heat map analysis of carbohydrate-active enzymes classes across all samples (b). C, rhizosphere soil of $C$. praeclara ; L, rhizosphere soil of L. secalinus ; N, non-rhizosphere soil.

TABLE S1 Soil properties of the bare bulk sandy soil

\begin{tabular}{|c|c|c|c|c|c|c|}
\hline $\begin{array}{l}\text { Available } \\
\text { potassium (mg } \\
\mathrm{kg}^{-1} \text { ) }\end{array}$ & $\begin{array}{l}\text { Total } \\
\text { potassium (mg } \\
\left.\mathrm{kg}^{-1}\right)\end{array}$ & $\begin{array}{l}\text { Available } \\
\text { phosphorus } \\
\left(\mathrm{mg} \mathrm{kg}^{-1}\right)\end{array}$ & $\begin{array}{l}\text { Total } \\
\text { phosphorus } \\
\left(\mathrm{mg} \mathrm{kg}^{-1}\right)\end{array}$ & $\begin{array}{l}\text { Total nitrogen } \\
\left(\mathrm{mg} \mathrm{kg}^{-1}\right)\end{array}$ & $\begin{array}{l}\text { Organic } \\
\text { carbon (mg } \\
\left.\mathrm{kg}^{-1}\right)\end{array}$ & $\mathrm{pH}$ \\
\hline $69.1 \pm 1.2$ & $230.5 \pm 7.6$ & $6.24 \pm 0.82$ & $270.0 \pm 5.4$ & $66.8 \pm 2.4$ & $672.0 \pm 8.4$ & $7.75 \pm 0.09$ \\
\hline
\end{tabular}

Note: Data are presented as mean $\pm \mathrm{SE},(\mathrm{n}=3)$ 

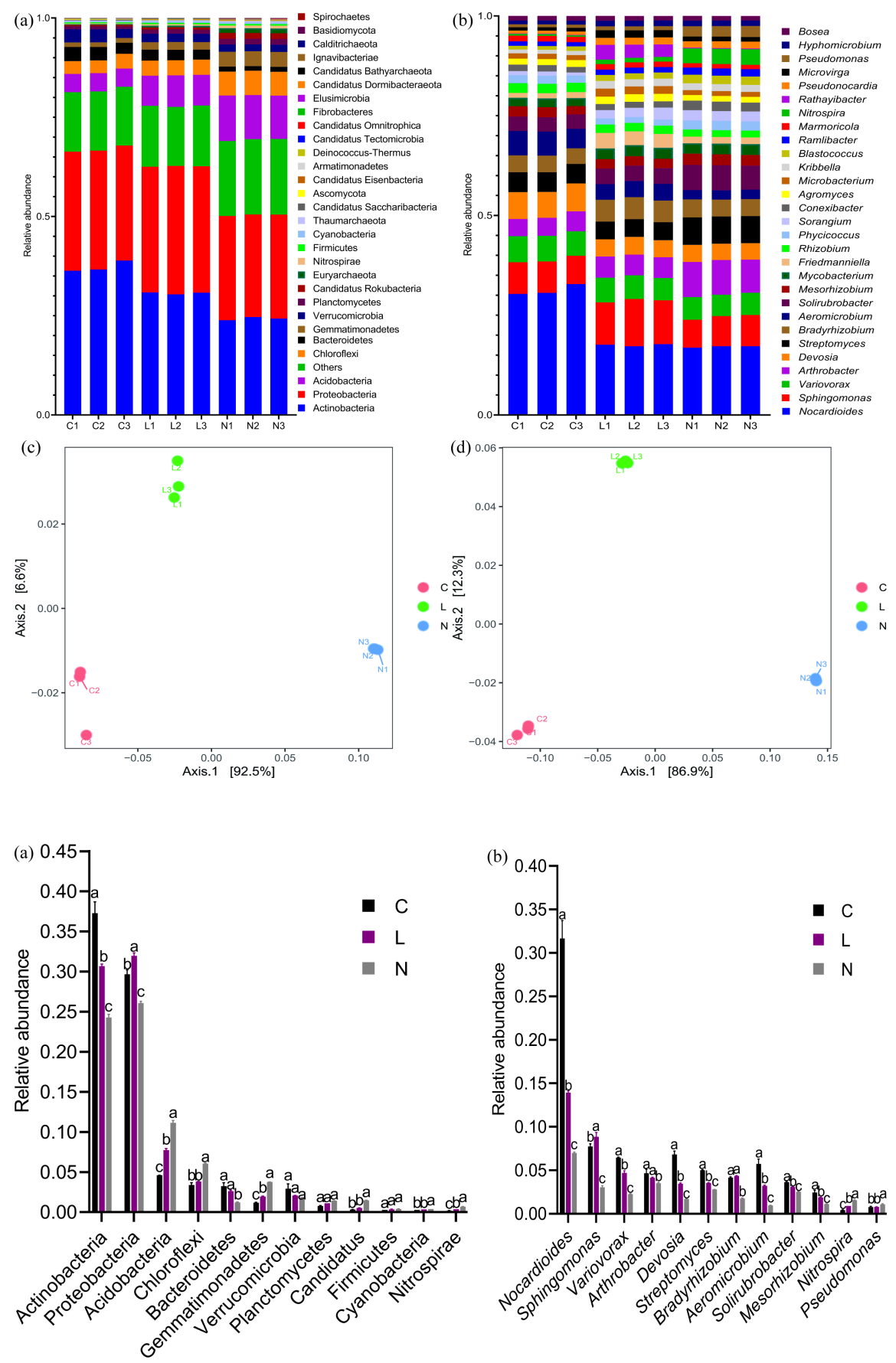

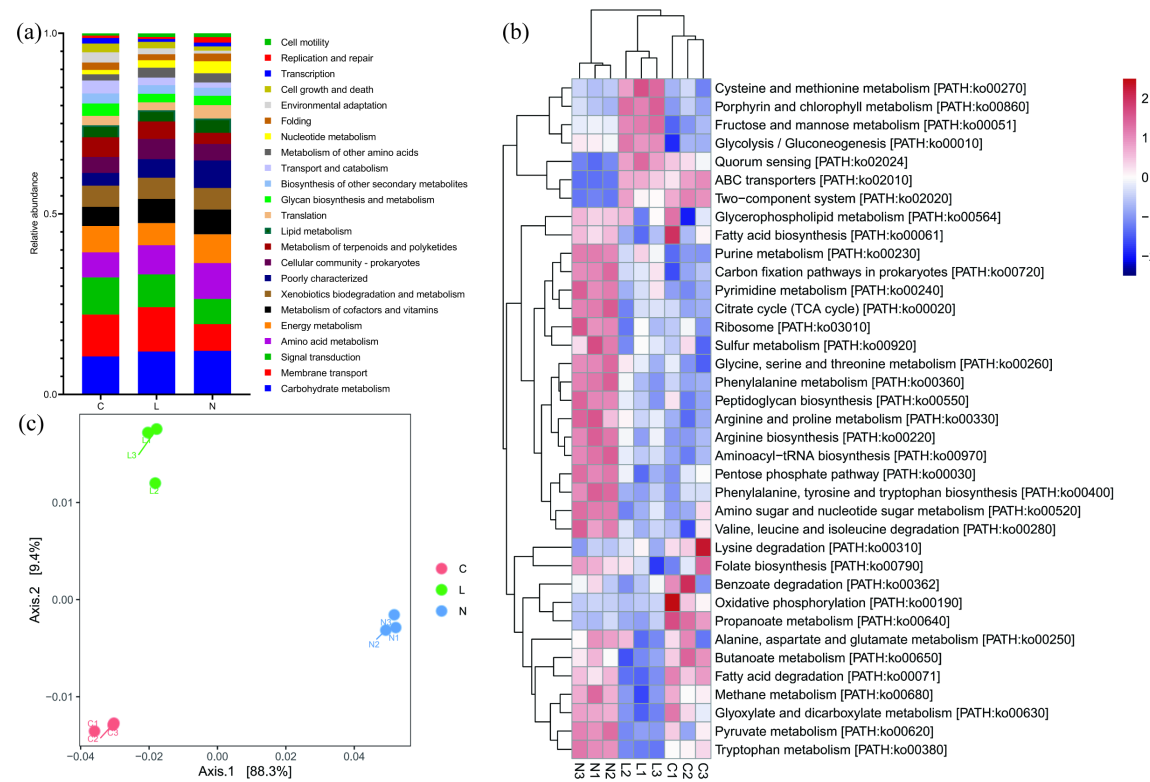


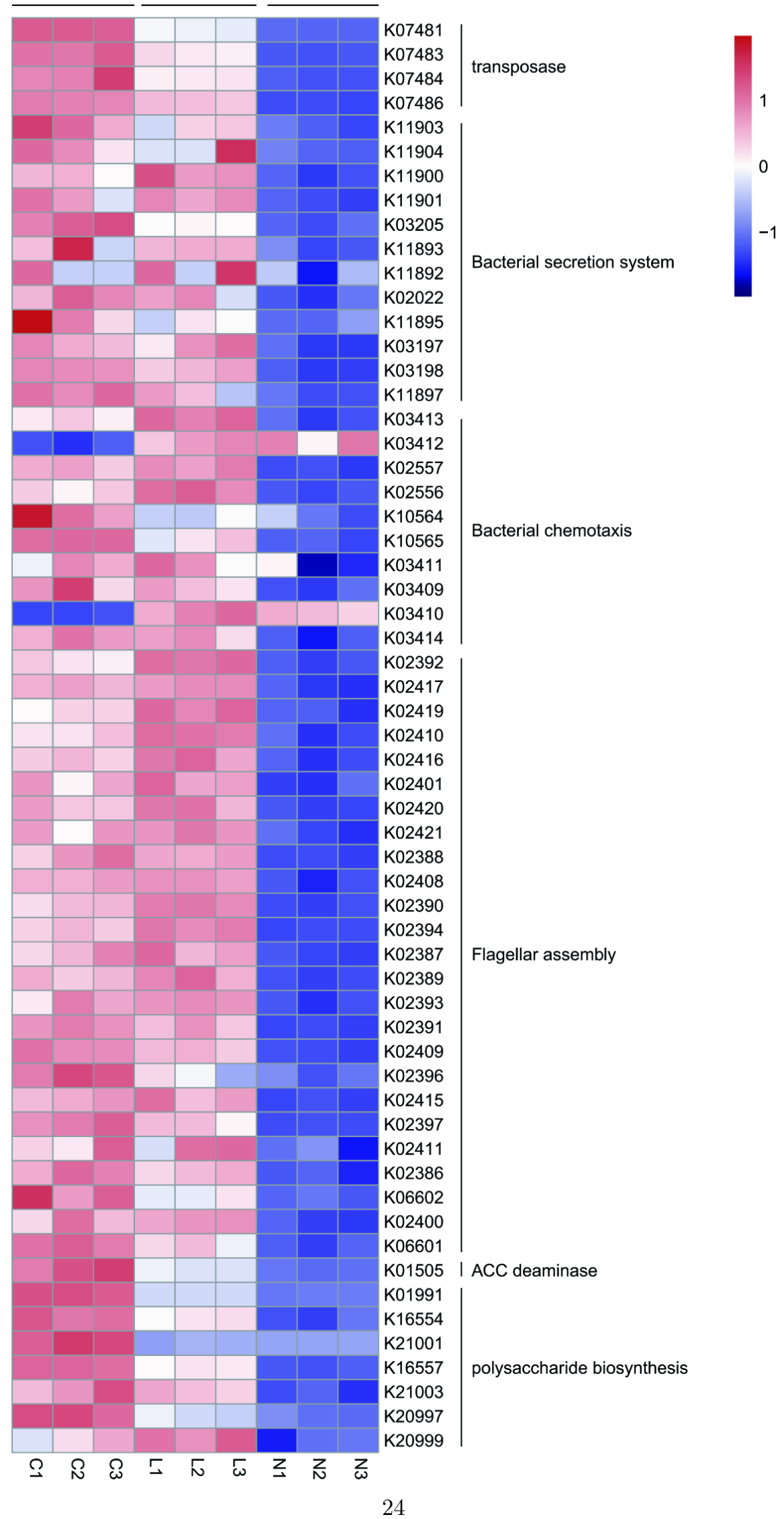




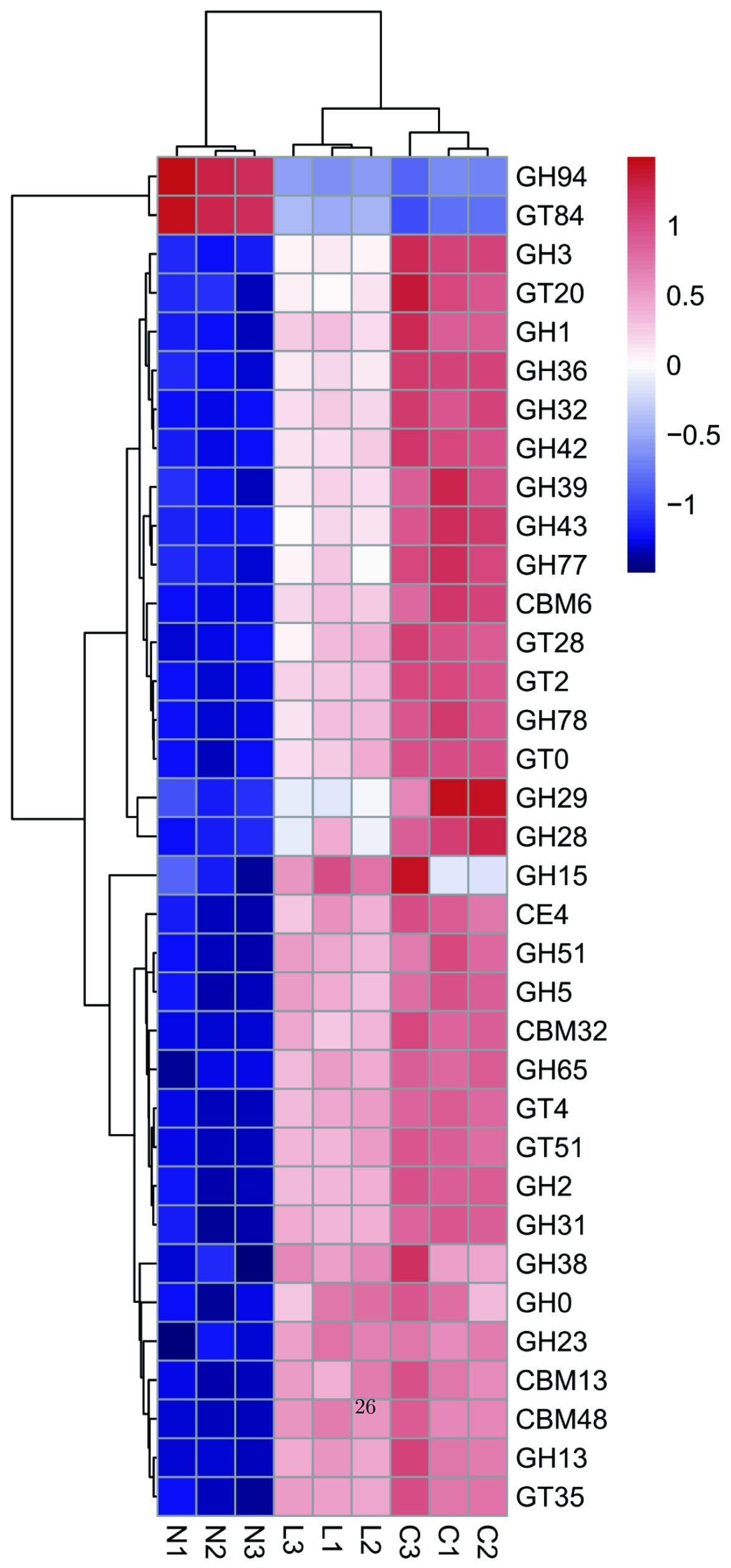




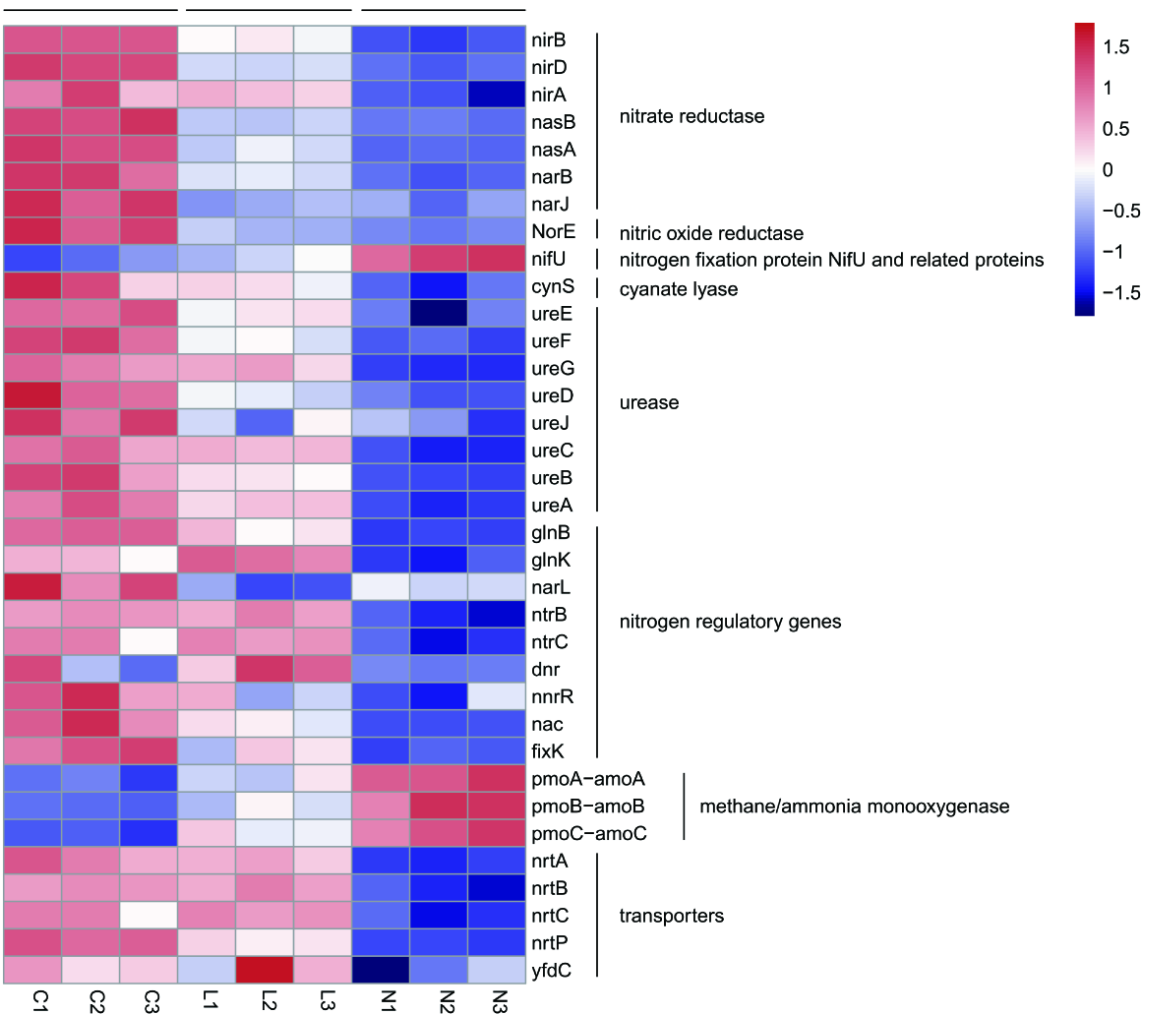




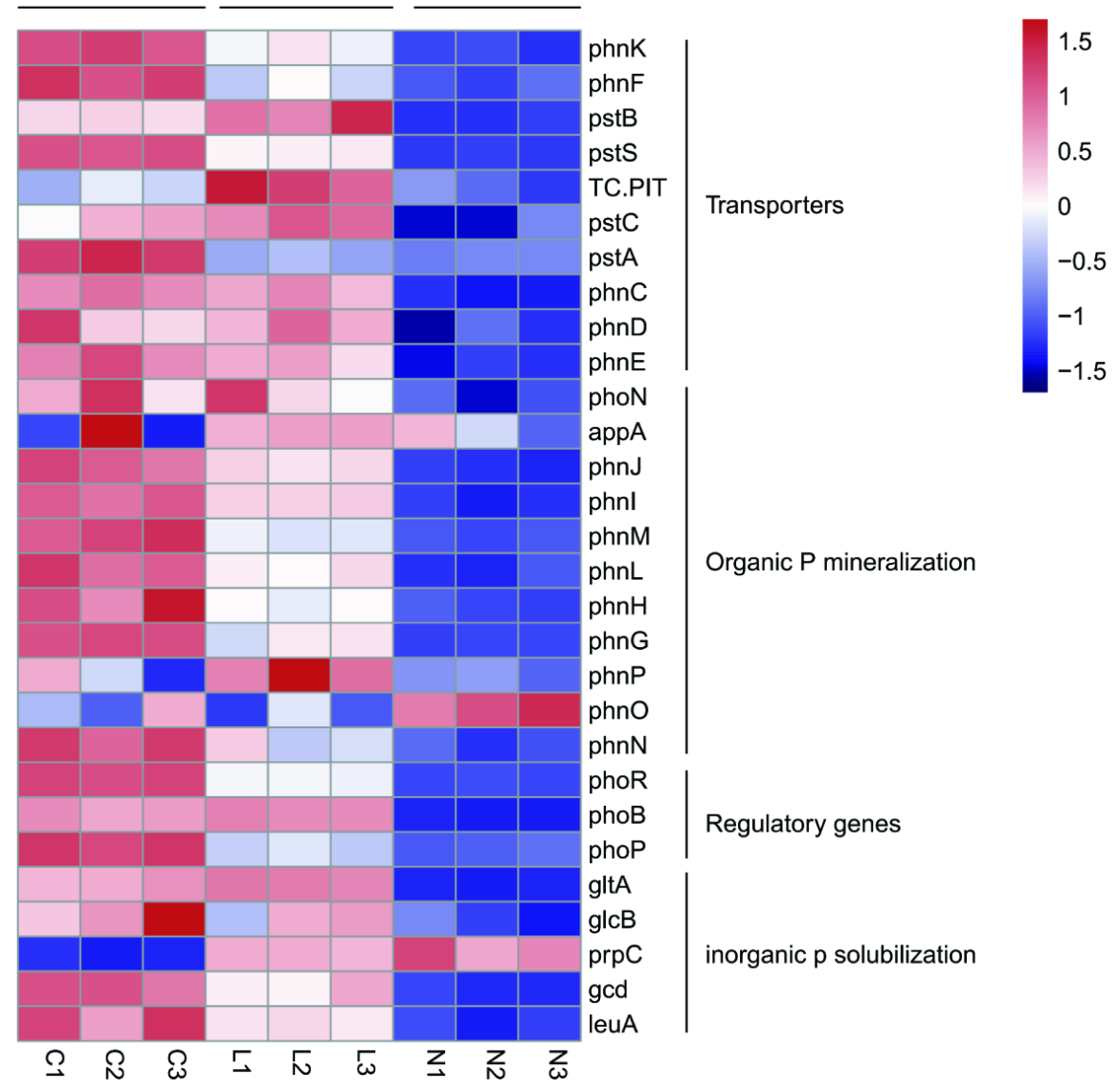

